\title{
Avanzando hacia un ágora virtual. Algunas aproximaciones sobre el estado actual de la cuestión
}

\begin{abstract}
Resumen
Este artículo trata del impacto que tienen las tecnologías de la información y de la comunicación (TIC) en la democracia y en la participación política. Así, partiendo del informe mundial de gobierno electrónico de Naciones Unidas, se describe cómo la e-democracia ha potenciado las pautas de la participación política no convencional (protestas), mientras que se muestra expectante sobre el estado de la cuestión del voto electrónico. Para finalizar, se propone la creación de un espacio denominado ágora virtual para reforzar una democracia más participativa y deliberativa.
\end{abstract}

\section{Palabras clave}

TIC, participación política, protestas, e-voto, ágora virtual.

\begin{abstract}
This article provides a comprehensive picture of the impact that information and communication technologies (ICTS) have on democracy and political participation. Therefore, based on the e- world report on governments of the United Nations, it is described how e-democracy has enhanced non-conventional political participation (protests), while there is expectation about the state of affairs of the e-vote. Finally, the creation of a site called a virtual agora is proposed to reinforce a more participatory and deliberative democracy.
\end{abstract}

\section{Keywords}

ICTs, political participation, protests, e-vote, virtual agora.

1 Irene Belmonte Martín es Profesora Colaboradora de la Universidad Miguel Hernández (España) y Doctoranda de Ciencia Política y de la Administración de la Universidad de Alicante (España). Ha impartido docencia en diversas titulaciones como Antropología, Periodismo, y Ciencias Políticas y de la Administración, sobre: Sistemas Electorales y Sistemas de Partido, Fundamentos de Ciencia Política, Comportamiento Político y Electoral, Política Comparada, Análisis del Entorno Social y Político, y Política Social. Su línea de investigación principal se desarrolla sobre la base de la modernización de la administración pública, especialmente en lo que se refiere a la adaptación de la gestión tributaria local a la Gobernanza y el Nuevo Servicio Público. Otras líneas de su trabajo se encuadran en: el análisis de las posibilidades de las NTIC aplicadas al gobierno, el management del tercer sector y la evaluación de las políticas públicas de igualdad en los Estados del Bienestar. 


\section{Introducción}

Las nuevas tecnologías de la información y de la comunicación (en adelante, NTIC o simplemente TIC) están fuertemente imbricadas en el modus vivendi de los ciudadanos en nuestras sociedades modernas y líquidas (Bauman, 2007). De hecho, resulta cada vez más natural la gestión de ciertas situaciones y la resolución de los problemas cotidianos a través de internet o de nuestros dispositivos móviles, como la consulta de las noticias diarias, el abastecimiento de los hogares, la organización del ocio, la descarga del entretenimiento, las acciones relacionadas con el comercio y los servicios financieros en su más amplia acepción, el cumplimiento de las obligaciones fiscales así como otras muchas otras y variadas actividades personales y sociales. Si un ciudadano no está en la red (Facebook, Linkedin o Twitter, entre muchas otras) y/o no aparece en Google, simplemente no existe. Somos, en definitiva, homo digitalis.

Aunque con cierto retraso y a un ritmo algo más lento con respecto a la actividad privada, la esfera pública también ha ido incorporando y, de hecho se adapta, al enorme potencial de las TIC a sus actividades, ya sea mediante la aplicación de medios de comunicación no convencionales (ya no nos resulta extraño recibir la notificación de una resolución administrativa, como una beca o la devolución de los impuestos, a través de un Short Message Service, SMS) 0 bien a través de internet. También estamos completamente adaptados a consultar las webs institucionales de las administraciones públicas, el perfil en Facebook de los partidos políticos (que nos interesan o disgustan), así como seguir por Twitter los comentarios de los políticos de nuestro entorno. Los ciudadanos digitales ya no se contentan con ser unos pasivos receptores de información a través de las TIC, también reclaman ser actores políticos activos (Ramos, 2010). El paso de era, de la "Sociedad Industrial" a la "Sociedad de la Información" (Castells, 2001), no debe quedarse acotado al campo del conocimiento meramente tecnológico, sino que debe implicar un avance y un cambio en la cultura política. Tanto es así que han irrumpido con fuerza los nuevos términos de e-democracia, e-gobierno, e-administración, e-gobernanza y gobierno abierto. Todos los anteriores conceptos hacen referencia a la aplicación de las TIC al ámbito público; a la participación política; a los procesos de elección de gobernantes, al diseño de políticas públicas; a la toma de decisiones políticas; a la gestión administrativa; a la rendición de cuentas, etc., y por esto, todos ellos están asumiendo un papel de indiscutible presencia y protagonismo en la disciplina y los estudios de la Ciencia Política y de la Ciencia de la Administración.

\section{El índice mundial de desarrollo del e-gobierno}

Según el informe sobree-gobierno que elabora bianualmente Naciones Unidas, existe un constante e interrumpido crecimiento en todos los indicadores del índice de desarrollo de e-gobierno en el mundo. Esto refleja que los países, en general, han mejorado y ampliado la prestación de servicios on line para satisfacer las demandas y necesidades de su ciudadanía. Este índice de desarrollo del e-gobierno es un indicador estadístico que incluye como parámetros: a) cómo se presenta la información en los distintos canales tecnológicos; b) su acceso y utilización; c) la capacidad de prestación del servicio por parte de los distintos gobiernos, y d) la participación ciudadana en un sentido bidireccional y su interconexión (United Nations, 2012). Por regiones, Europa, América y Asia se encuentran por encima de la media mundial (que en 2012 se situaba en 0.4877 frente al 0.4406 del año 2010), mientras que África y Oceanía se encuentran claramente por debajo del resto. Resulta cuanto menos curioso destacar que los países que lideran el ranking son: República de Corea, Países Bajos, Reino Unido, Dinamarca y Estados Unidos. El país latinoamericano mejor posicionado en el listado es Colombia, que se encuentra en la posición 17 de los 20 líderes emergentes, que siguen a la veintena que está en cabeza.

El citado informe también pone de manifiesto que "there's a strong political emphasis in e-participation" (United Nations, 2012, pág. 44), por lo que nos encontramos con ciudadanos políticos on line; y su grado de implicación dependerá tanto de sus posibilidades de acceso a las tecnologías como al liderazgo de las políticas públicas de los gobiernos hacia esta dirección.

\section{La participación política y las Tic}

Sin embargo, complementariamente y en lo que se refiere a la participación política, "most people do not care much about politics and get involved in the political realm only exceptionally" (Blais, 2011, pág. 181). Así, en cuanto se desagregan las formas que adopta la participación política, seobservaun claroy continuado descenso en la participación electoral, en prácticamente todos los países, al tiempo que aparece un más que sensible incremento en la participación 
no convencional, haciéndose especialmente significativa la que se refiere a las protestas políticas (Dalton, 2009). A modo de ejemplo, resultan en este sentido claramente reveladoras las protestas lideradas por el movimiento $15 \mathrm{M}$ en mayo de 2011 en España, que se extendieron por todo el mundo, dando lugar a las manifestaciones mundiales el $24 \mathrm{O}$ en prácticamente las grandes capitales europeas en respuesta al hastío de la forma de hacer política tradicional, el movimiento de protestas de la primavera árabe que ha supuesto incluso la caída e inestabilidad de los gobiernos en la región de Oriente próximo, así como las protestas en el emblemático parque Gezi de Estambul durante el verano de 2013 en respuesta de lo que es considerado una involución del Estado laico en Turquía, y al intento de conquista del islamismo. También, a principios de este 2014, son cada vez más frecuentes y populosas las protestas en Ucrania, que enfrenta a una ciudadanía pro Rusia (visión que defiende el gobierno), o a favor de la Unión Europea (la oposición).

De lo expuesto hasta el momento, podemos resaltar dos evidencias: a) la primera, que todas estas manifestaciones y protestas no hubieran tenido ni la magnitud ni el alcance mediático si no llega a ser por las TIC, y especialmente por lo que se conoce como redes sociales, y b) que especialmente algunos ciudadanos, en particular los más jóvenes y habituales usuarios de las TIC, han sustituido el voto por otras manifestaciones de participación política no convencional.

Así, mientras que "young citizens are much less likely to vote" (Blais, 2011, pág. 169), son mucho más sensibles a la participación política mediante protestas y el uso las TIC a través de las redes sociales.

De todo lo antedicho, se observa que la contribución de las TIC a la democracia es mucho más sencilla de llevar a cabo a través de las formas de participación política no convencional que por la electoral.

\section{La participación electoral y las TIC}

Desde el planteamiento 'ciberoptimista', se considera que el voto por la red reforzará la democracia en la medida que, previsiblemente, incrementará la participación. Sin embargo, la posibilidad de emitir el voto electrónico remoto (es decir, por internet o en red) para elegir a nuestros representantes aún parece muy lejana. Así, el desarrollo del estado de la técnica actual no permite garantizar aún que la votación en red esté a la altura de calidad democrática de la votación tradicional.

El sufragio, para que sea considerado realmente democrático, ha de satisfacer los siguientes requisitos: universal, igual, directo, secreto y libre. En verdad, además de las dudas sociológicas que suscitan la brecha digital y su propia aceptación por la ciudadanía, todavía las TIC no han conseguido resolver ciertas amenazas asociadas al e-voto, a saber: la autentificación, la fiabilidad, la veracidad y el anonimato del emisor de la preferencia, así como garantizar la imposibilidad de coacción, la neutralidad y la precisión (Belmonte, 2007). La brecha digital (digital divide), que hace referencia a la desigualdad de acceso y uso a las TIC, es un fenómeno multidimensional (Norris, 2001, pág. 4), que se nutre de componentes sociales, económicos y políticos, además la oferta y demanda tecnológica, puede contribuir a hacer aún más "dual" la sociedad y, por ende, a sus ciudadanos. Es por ello, que los Estados están adoptando una actitud cada vez más reactiva para minimizarla. En cualquier caso, y a pesar de importantes avances, especialmente en Europa y en el continente americano, "progres on the digital divide is far from satisfactory, though rapid dispersión of mobile technology gives hope for improvement" (United Nations, 2012, pág. 5).

Por todo ello, cabría afirmar que el voto electrónico no es en ningún caso una panacea política, y ha de ser considerado como una herramienta complementaria para la mejora estructural de los procesos electorales (Reniu, 2008). Por ejemplo, cuando la participación es tan baja que puede socavar su legitimidad y para garantizar la fiabilidad y rapidez en el recuento y transmisión de resultados. También, el e-voto, puede ser útil para mejorar los mecanismos de democracia directa (vía referendo) y contrarrestar la corrupción, pero no hay que olvidar que la democracia implica también deliberación (Cotarelo, 2010, pág. 66). Por ello, creemos conveniente aclarar que una democracia más participativa digitalmente no conseguirá mejorar su calidad en la medida que no contribuya a la creación de una verdadera ágora virtual de deliberación, de generación de ideas y de debate en un entorno de plena información, libertad e igualdad de condiciones para la ciudadanía. Posiblemente, la democracia no necesita de importantes innovaciones estructurales (Sartori, 2009, pág. 144), sino de una ciudadanía vertebrada en el sentido contrario al "hombre masa" que describía Ortega y Gasset en La rebelión de las masas. 


\section{Algunas conclusiones y propuestas}

Las TIC han irrumpido con fuerza en la esfera política. Las redes sociales han constituido el canal principal para llevar a cabo las protestas políticas. Al mismo tiempo, los jóvenes confían cada vez menos en la efectividad del voto, y hacen política a través de las posibilidades que les ofrece internet para la participación política no convencional. Así, las protestas fluyen con toda rapidez y se universalizan por las redes sociales. Sin embargo, el voto electrónico no puede garantizar, ni de lejos aún, las condiciones de seguridad y fiabilidad de los escenarios tradicionales. Así, considerando enriquecedor todas estas posibilidades que incorpora la tecnología a la calidad democrática, en cada una de sus variantes, se pretende hacer reflexionar al lector sobre el camino para llegar a un ágora virtual, que vertebre plenamente la sociedad democrática.

\section{Referencias}

Bauman, Z. (2007). Vida líquida. Barcelona: Paidós.

Belmonte, I. (2007). "¿Pueden ser las nuevas tecnologías un instrumento para reforzar las democracias?". Revista de la Facultad de Ciencias Sociales y Jurídicas de Elche, Volumen I, número 2, 1-23.
Blais, A. (2011). "Political Participation". En L. N. LeDuc, Comparing Democracies 3. Elections and Voting in the 21th Century (págs. 165-184). London: Sage Publications Ltd.

Castells, M. (2001). La galaxia internet. Barcelona: Plaza \& Janés.

Cotarelo, R. (2010). La política en la era de internet. Valencia: Tirant lo blanch.

Dalton, R. J. (2009). Citizen Politics: Public Opinion and Political Parties in Advanced Industrial Democracies, 6th edition. Washington: CQ Press.

Ramos, C. (2010). \#Democracia Hacker. El poder de los ciudadanos. Granada: Algon Editores.

Reniu, J. M. (2008). "Ocho dudas razonables sobre la necesidad de voto electrónico". Revista de Internet Derecho y Política, número 6, 32-44.

Sartori, G. (2009). La democracia en 30 lecciones. Madrid: Taurus.

Tricas, F. (2007). "El gobierno electrónico: servicios públicos y participación ciudadana". Fundación Alternativas. Documento de trabajo 109/207.

United Nations (2012). "Global E-Government Survey". Disponible en: http://unpan3.un.org/egovkb/global_ reports/index.htm 